This is the author's manuscript for publication. The publisher-formatted version may be available through the publisher's web site or your institution's library.

\title{
Identification of windbreaks in Kansas using object-based image analysis, GIS techniques and field survey
}

Kabita Ghimire, Mike W. Dulin, Robert L. Atchison, Douglas G. Goodin, J. M. Shawn Hutchinson

\section{How to cite this manuscript}

If you make reference to this version of the manuscript, use the following information:

Ghimire, K., Dulin, M. W., Atchison, R. L., Goodin, D. G., \& Hutchinson, J. M. S. (2014). Identification of windbreaks in Kansas using object-based image analysis, GIS techniques and field survey. Retrieved from http://krex.ksu.edu

\section{Published Version Information}

Citation: Ghimire, K., Dulin, M. W., Atchison, R. L., Goodin, D. G., \& Hutchinson, J. M. S. (2014). Identification of windbreaks in Kansas using object-based image analysis, GIS techniques and field survey. Agroforestry Systems, 88(5), 865-875.

Copyright: @ Springer Science+Business Media Dordrecht 2014

Digital Object Identifier (DOI): doi:10.1007/s10457-014-9731-4

Publisher's Link: http://link.springer.com/article/10.1007/s10457-014-9731-4

This item was retrieved from the K-State Research Exchange (K-REx), the institutional repository of Kansas State University. K-REx is available at http://krex.ksu.edu 


\title{
Identification of windbreaks in Kansas using object-based image analysis, GIS techniques and field survey
}

Kabita Ghimire • Mike W. Dulin • Robert L. Atchison • Douglas G. Goodin • J. M. Shawn Hutchinson

K. Ghimire ${ }^{1}$, D. G. Goodin,J. M. Shawn Hutchinson (Department of Geography, Kansas State University,Manhattan, KS 66506-2904, USA, 'e-mail: kabita@ksu.edu)

M. W. Dulin (US Army Corps of Engineers, Kansas City,MO 64106, USA)

R. L. Atchison (Kansas Forest Service, Kansas State University,Manhattan, KS 66506, USA)

Received: 4 March 2014 / Accepted: 16 July 2014

Springer Science+Business Media Dordrecht 2014

Citation: Ghimire, K., M.W.Dulin., R.L.Atchison., D.G. Goodin and J.M. S. Hutchinson. 2014. Identification of windbreaks in Kansas using object-based image analysis, GIS techniques and field survey. Agroforestry Systems. 88(5). 865-875

\begin{abstract}
Windbreaks are valuable resources in conserving soils and providing crop protection in Great Plains states in the US. Currently, Kansas has no up-to date inventory of windbreaks. The goal of this project was to assist foresters with future windbreak renovation planning and reporting, by outlining a series of semi-automated digital image processing methods that rapidly identify windbreak locations. There were two specific objectives of this research. First, to develop semi-automated methods to identify the location of windbreaks in Kansas, this can be applied to other regions in Kansas and the Great Plains. We used a remote sensing technique known as object-based image analysis (OBIA) to classify windbreaks visible in the color aerial imagery of National Agriculture Imagery Program. We also combined GIS techniques and field survey to complement OBIA in generating windbreak inventory. The techniques successfully located more than 4500, windbreaks covering an approximate area of 2500, hectares in 14 Kansas counties. The second purpose of this research is to determine how well the results of the automated classification schemes match with other available windbreak data and the selected sample collected in the field. The overall accuracy of OBIA method was $58.97 \%$. OBIA combined with 'heads up' digitizing and field survey method yielded better result in identifying and locating windbreaks in the studied counties with overall accuracy of $96 \%$.
\end{abstract}

Keywords Shelterbelts, Soil conservation, Crop protection, Kansas, Great plains

\section{INTRODUCTION}

Windbreaks provide a number of environmental benefits for semi-arid regions throughout the world. Also known as shelterbelts or living fence, they are valuable resources for conserving soil and providing crop protection in Kansas, as well as in other Great Plains states (Brandle et al., 2004). The primary function of windbreaks is to reduce wind velocity and offer protection from the severe weather of the Great Plains. Windbreaks also provide wildlife habitat, sources of fuel and fodder, provide recreational opportunities and improve energy efficiency for farmsteads (Cable, 1999; SAF, 2008). With the change in the agricultural landscape, the functional value of 
windbreaks is also changing in North American Midwest. Studies have shown that windbreaks play important role in livestock industry and its operation. They are beneficial in protecting young animals from cold during winter and spring, help increase their feeding efficiency, protect feedlots, pastures and calving areas (Quam, V et al., 1994; Tyndall 2009). Windbreaks are in demand in the Great Plains also to mitigate odor from livestock industry and for aesthetic appeal of agricultural lands (Tyndall 2009; Grala and Tyndall, 2010) and efforts to renovate older windbreaks have increased in recent years (Atchison et al.,2010).

The first major planting of windbreaks in the United States occurred during the1930's in response to the Dust Bowl (Read 1958; Droze, 1977; Brandle et al., 2004). Through the Prairie States Forestry Project (PSFP; 1935-1942), 145 to 200 million trees and shrubs were planted into 30,000 shelterbelts, which totaled 18,600 miles in length from the Canadian border of North Dakota south to the Texas Panhandle (Read, 1958, Droze, 1977; Croker, 1991).

Assessment of the size, condition and location of windbreaks since the dustbowls days has been marginal at best, as USDA Forest Service Forest Inventory and Analysis Program measurements did not capture the majority of the resources. Evaluations of the PSFP efforts in 1954 reported 42 percent of the windbreaks surveyed in good or excellent condition, 31 percent fair, and 19 percent poor. The remaining 8 percent had been removed (Read, 1958). Sorenson and Marotz (1977) expressed concerns that windbreaks in Kansas were being removed and not replaced estimating a 20\% loss between 1962 and 1970. Due to the introduction of irrigation systems in the 70s, a 1980 USDA report documented 119 windbreaks removed in 32 Kansas counties. Castonguay and Hansen (1984) reported that wooded stripes and windbreaks in Kansas covered approximately 136,000 hectares and were more than 54,000 miles long. In 1992, Natural Resource Conservation Service (NRCS) Natural Resource Inventory (NRI) found 78,000 windbreaks in the state totaling 46,134 hectares with a collective length of 20,000 miles. Thirteen percent were found to be in excellent condition, 38 percent good , 34 percent fair and 15 percent poor (USDA,1994). In spite of an educational campaign and the conservation efforts by government agencies the number of windbreaks on the Great Plains has been decreasing and their condition is deteriorating (Cable, 1999). The most recent windbreak assessment in Kansas occurred through the Great Plains Initiative in 2008 and 2009, which estimated 289,577 windbreaks stretching 43,436 miles providing wind protection to 1.2 million acres of land (Atchison et al., 2010). Though the establishment of new field windbreaks to address windblown 
soil erosion has become passé, Atchison et al (2010) reported 2.9 million acres of cultivated cropland in Kansas (12\%) exceeds tolerable limits for soil erosion. The tolerable limit is around 1.3 tons/acre/year (NRI NRCS 2010).

Current drought and projections for continuing drought associated with climate change combined with a possible move back to dry-land farming as the Ogallala aquifer is depleting, all point to the important conservation role field windbreaks offer to the Great Plains. Yet, there is little good science to efficiently document windbreak location, size, or condition. Therefore, it is now timely to build upon previous work of NRCS and additional windbreak research projects to develop methods for the rapid identification of windbreak location and assess their condition while promoting their important role as a conservation tool in the Great Plains.

\section{PURPOSE AND OBJECTIVES OF THE STUDY}

The purposes of this research are twofold. First, we aim to develop semi-automated methods to identify the location of windbreaks in Kansas that can be applied to other counties/regions in Kansas and the Great Plains. To achieve this goal, we used a remote sensing approach based on Object-Based Image Analysis (OBIA) to classify windbreaks visible in the color aerial imageries of 2008/2010/2012 National Agriculture Imagery Program (NAIP). Attributes from four spectral bands (blue, green, red, and near infrared) in the NAIP imagery were used in the segmentation and classification process.

The second purpose of this research is to determine how well the results of the automated classification schemes match with other available windbreak data and the selected sample collected in the field.

\section{STUDY AREA}

The study area consists of 14 counties from the western Kansas Forest District (Figure 1). Out of the fourteen, seven counties are associated with Coronado Crossing Resource Conservation and Development Council (RC \& D). They are Ford, Clark, Gray, Haskell, Hodgeman, Meade, and Seward. The other seven counties are from Smoky Hill region and they are Wallace, Logan, Gove, Trego, Ellis, Russell and Ellsworth. Ford County served as the pilot county for the method development. The methods developed were applied in the rest of the counties in the study area. 
Agricultural cropland dominates the land cover within these counties, while mixed or short grass prairies make the majority of native vegetation (Goodin et al., 2002). Land uses related to the cattle industry also make a major part of the landscape with many areas being used as grazing land, livestock feed production and large-scale feedlots (Harrington, 2001).

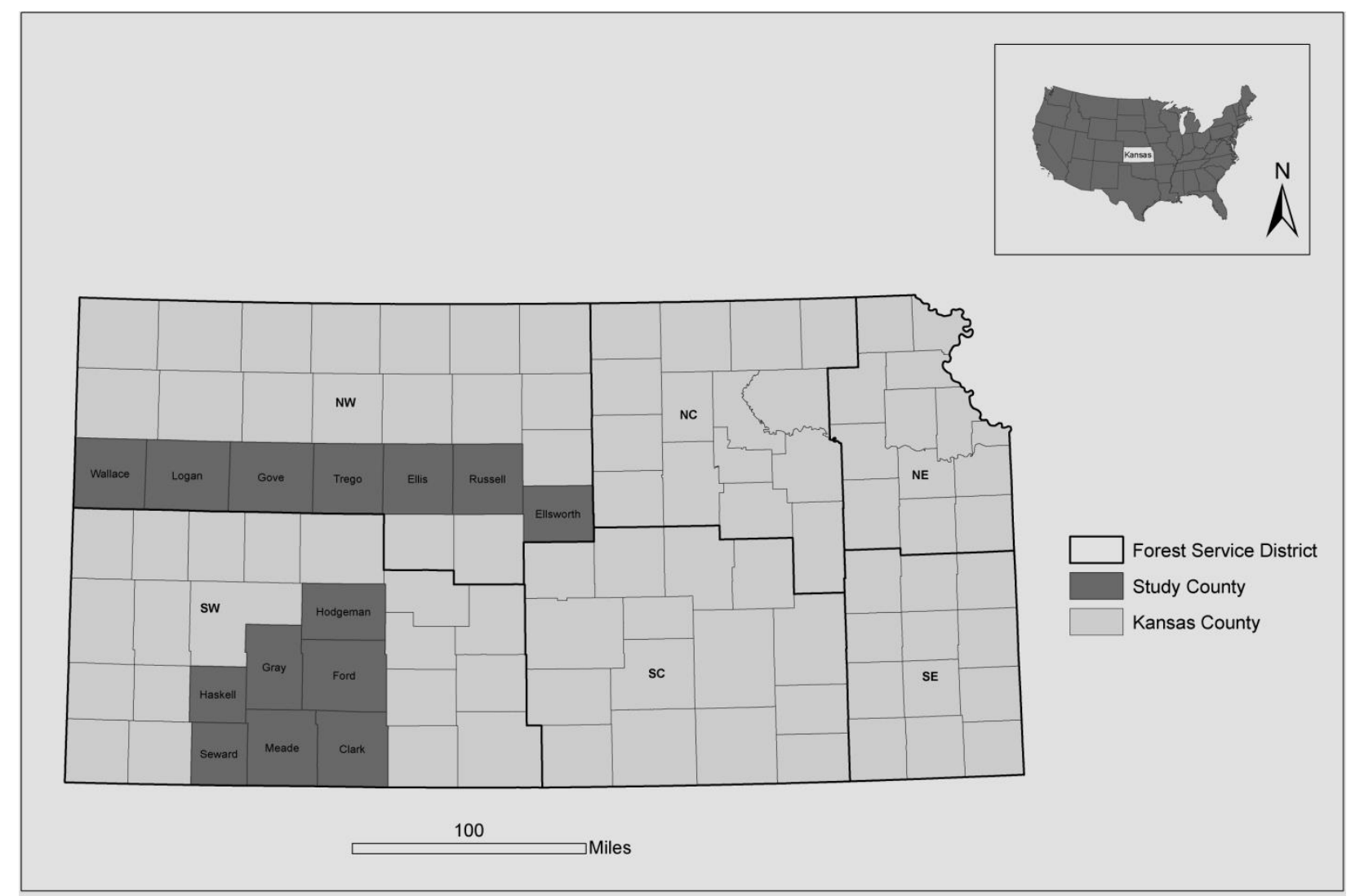

FIGURE 1: KANSAS REFERENCE MAP AND STUDY AREA WITHIN KANSAS FOREST SERVICE DISTRICTS

\section{METHODS}

\subsection{Remote sensing for feature extraction}

Remote sensing is commonly used for the identification, extraction, and classification of Land Use/Land Cover (LULC) types (Quattrochi et al., 1989; Koch et al., 2007). Extracting thematic information from imagery is typically accomplished through supervised or unsupervised classification approaches (Jensen 2005; Richards and Xiuping 2005). Both supervised and unsupervised classification methods have traditionally been accomplished on a per-pixel basis. Per pixel classification takes into account only the spectral value of a single 
pixel, which limits its capability to identify 'features' and process very high resolution data (Jensen 2005). More recently, object-based classification methods have been gaining in popularity. Object-based classification groups homogeneous pixels through a segmentation process and converts them to multi-pixel shapes that later become the basis for classification (Jensen 2005).

\subsection{Object-Based Image Analysis (OBIA)}

Object-based classification considers shape and context of landscape features or objects along with the position, size and spectral characteristics of individual objects during classification (Jensen 2005; Blaschke 2010). Essentially, object-based classification allows a classification scheme to be based on the shape of objects or features rather than simply the spectral reflectance of single pixel (Baatz et al., 2004).

Often, object-based classification has shown its usefulness in classifying entire images and also for single feature extraction. Using certain spatial and spectral criteria, it is the objective of this research to isolate windbreaks from all other land cover features and assess their condition using different spectral and textural properties. By taking advantage of the unique ability of object-based classification to classify features based on their shape, windbreak features should be easily distinguished from all other land cover features that share similar spectral properties. In addition, using this automated technique it should help decrease the amount of time required to inventory windbreaks by eliminating much of the field survey methods employed by Read (1958).

The non-spectral classification criteria are crucial for accurate classification of windbreaks for two reasons. First, windbreaks are usually linear strips of tree plantings. A riparian forest area would exhibit similar spectral reflectance characteristics and make it difficult to distinguish it from a windbreak without first considering some shape criteria in the classification. Second, object-based classification software package we are using allow for the isolation of features of interest.This means that, based on certain shape and spectral parameter settings, one can eliminate features in the image that are not relevant before beginning the classification process, resulting in more efficient classification and image processing times.

\subsubsection{Image preprocessing}

The images used in this study were acquired from the 2008/2010/2012 NAIP. NAIP imagery has spatial and radiometric resolutions of 1 meter and 8 bits, respectively. Each image is 
multispectral in nature, and contains spectral data from four bands of the electromagnetic spectrum: blue (band 1), green (band 2), red (band 3), and near infrared (NIR) (band 4). The NAIP imageries were collected during the growing season (Williams and Davis 2013). Each NAIP image was resampled using the nearest neighbor technique at a factor of 6 to reduce image file size and speed computer processing (Parker et al., 1983; Dodgson, 1992).

\subsubsection{Image segmentation, segment merging and thresholding}

The ENVI Zoom 4.5 Feature Extraction Module (ITT Visual Information Solutions, Boulder, Colorado), which was used in this research, uses an edge-based algorithm developed by Robinson et al., (2002) to segment imagery. However, little research has been published using this software. (ITT Visual Information Solutions 2008). Several segmentation methods are available that can be used to isolate homogeneous pixels into proper objects. Here, an edge-based segmentation method and Support Vector Machine (SVM) classifier were applied using the ENVI Zoom 4.5 Feature Extraction Module (ITT Visual Information Solutions, 2008). The edgebased segmentation algorithm tends to operate faster than other approaches, such as bottom-up region merging, because it requires only scale level as an input parameter. Scale level is an area measure that determines the size of objects to be created. Scale parameter values range from 0 to 100 with segments decreasing in size as they move closer to 0 . We used a scale level range of 70-80. A county with longer windbreaks needed larger scale level value for segmentation. Similarly, if a county contains several small farmstead windbreaks scale parameters would need to be decreased to reduce the generalization of those windbreaks. County specific scale level range was also useful in differentiating windbreaks with riparian area, which has similar spectral properties. The scale level range of 70 -80 adequately defined segments between the windbreak and surrounding LULC types in the study area.

Segment merging, based on a Full Lambda-Schedule algorithm (Robinson et al. 2002) was then applied to identify and combine neighboring objects with similar spatial, spectral, and textural properties. After experimentation, a lambda value ranging from 50-60 was found to be most effective at merging segments within windbreaks while keeping them distinct from neighboring LULC types.

In addition to image segmentation and merging, a technique called thresholding was used to eliminate computed objects with mean spectral values that were not essential for identifying windbreaks. For this project, the only land use/land cover type of concern is the windbreak 
vegetation, so elimination of impervious features such as roads, houses, bare soil, and parking lots makes the process of correctly defining classes for the remaining vegetation types much simpler. Visual analysis showed that a minimum band threshold of 90 eliminated most impervious features. After thresholding, however, several non-windbreak vegetation LULC types (e.g., riparian areas, forest patches and croplands) remained in the image.

Using the segmentation parameters discussed previously generated thousands of objects in each county. This is largely because fragmentation within the classified featured class is very well captured by object-based approach. A larger-scale view $(1: 35,000)$ of several segmented objects within the study area is shown in Figure 2. Areas in white contain no data as they were masked out during the thresholding process.

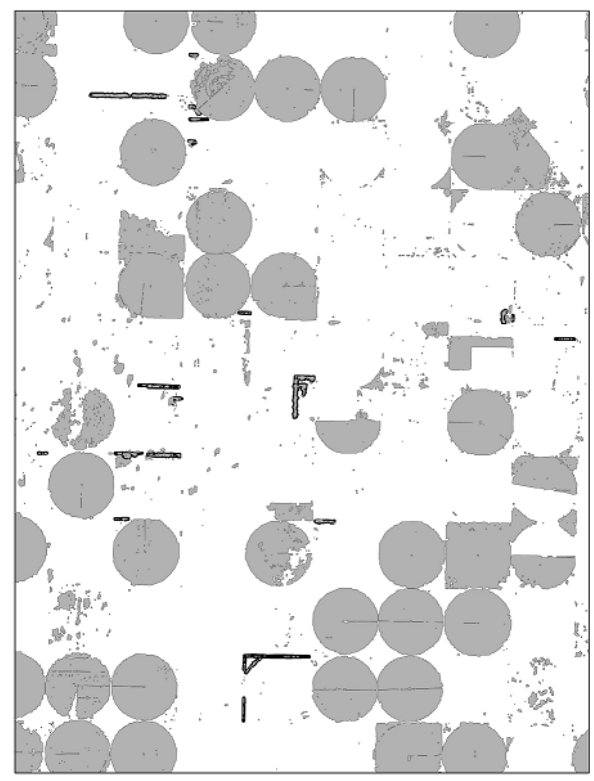

FIGURE 2: PORTION OF THE SEGEMENTED IMAGE OF VEGETATIVE FEATURES IN CLARK COUNTY (1:35,000 SCALE).THE WHITE SPACE REPRESENTS THE FEATURES REMOVED DURING THRESHOLDING PROCESS. CIRCLES REPRESENTS CROP FIELD WITH PIVOT IRRIGATION SYSTEMS. THE LINE REPRESENTS WINDBREAKS. REMAINING GREY PATCHES REPRESENTS EITHER TREE STANDS, SHRUBS, RIPARIAN AREA AND/OR SMALL FOREST PATCHES.

\subsubsection{Image classification}

After unwanted regions of the image were eliminated, attributes for use in classification were computed. These image attributes included those related to spatial geometry (e.g., area, length, roundness), spectral characteristics (e.g., pixel brightness values within objects), texture 
(e.g., measures of pixel variance and range), and band ratio (e.g., hue, saturation, and intensity of pixel values within objects). Object classification, using a supervised approach, followed the export of segments and their associated attributes. After inspecting the post-thresholding image, a set of custom classes was created to drive the supervised classification process (Table 1). Training sites were then established for each of the six classes.

\section{TABLE 1: LANDUSE/LANDCOVER (LULC) CATEGORIES USED IN THE CLASSIFICATION AND THEIR DESCRIPTION}

\begin{tabular}{|l|l|}
\hline LULC Type & Description \\
\hline Crops & $\begin{array}{l}\text { Live row crops including center pivot } \\
\text { irrigation land }\end{array}$ \\
\hline Tree Stands & $\begin{array}{l}\text { Individual stands of trees/shrubs not linear in } \\
\text { nature and not near water feature }\end{array}$ \\
\hline Riparian & $\begin{array}{l}\text { Long irregularly shaped stands of trees } \\
\text { bordering water features }\end{array}$ \\
\hline Windbreaks & $\begin{array}{l}\text { Linear strips of trees planted near farm houses } \\
\text { and crop fields likely to have jagged edges } \\
\text { conforming to the shape of outer edge trees }\end{array}$ \\
\hline Manicured & $\begin{array}{l}\text { Vegetative features under human } \\
\text { management such as golf courses, lawns } \\
\text { Landscapesall fields, soccer fields, football fields }\end{array}$ \\
\hline Ditches & $\begin{array}{l}\text { Long linear features running parallel to roads } \\
\text { and rail road tracks containing few trees and } \\
\text { smooth edges }\end{array}$ \\
\hline
\end{tabular}

The Discrete Capability Index (DCI) was used to select the optimal set of object attributes for classifying the features that remained after thresholding (ITT Visual Information Solutions, 2008).

The final step in this object-based image classification involved using the SVM algorithm with a radial basis function (RBF) kernel. SVM uses a training set of instance-label pairs to map vectors into a possibly infinite number of spatial dimensions by the function $\Phi$ (Hsu et al., 
2008). The SVM algorithm then uses optimization methods to divide numeric attributes into upper and lower margins based on a set number of hyper-planes that split the data into their respective classes (Huang and Zhang, 2008; Hsu et al., 2008). Another classification algorithm often used in object-based classifications, K Nearest Neighbor, was avoided here for two primary reasons: (1) windbreaks are not distributed in a uniform manner across the landscape, so similar nearby features can't reliably be classified as windbreaks, and (2) misleading results would likely result given that very large areas were masked out of the image during thresholding, where objects containing no similar spectral properties consistent with that of a windbreak were excluded from analysis.

\subsubsection{Accuracy Assessment}

To assess the accuracy of the object-based windbreak classification using a traditional error matrix approach, a number of random sample points within each of the six supervised classification-training sites were generated. The proper number of random samples was determined using the equation from Fitzpatrick-Lins (1981). Fitzpatrick-Lins, K. 1981. Congalton (1991) and Congalton and Green (1999) suggest that each class have at least 50 random points when dealing with large areas (i.e., 1 million ha or more), so each class was assigned at least 50 random points in order to construct the error matrix. Once random samples were generated within each class, the error matrix was populated by inspecting the original NAIP image in the area of each random point. Knowledge-based interpretation of LULC features was used to determine if the object-based classification classes matched the actual LULC visible in the aerial photograph. Because the windbreak category was the only class for which accuracy was relevant, a 2 × 2 error matrix of non-windbreak and windbreak classes was constructed (Table 2).

Producer and user accuracies for each class were calculated after the error matrix was populated. Finally, the Kappa value was calculated to provide an estimate of how much better the object-based classification performed relative to a random assignment of classes to each object (Jensen 2005).

TABLE 2: ERROR MATRIX COMPILED FROM A RANDOM DISTRIBUTION OF SAMPLE POINTS FOR NON-WINDBREAK (NWB) AND WINDBREAK (WB) CLASSES FROM ALL FOURTEEN COUNTIES 


\begin{tabular}{|l|c|c|c|c|}
\hline & NWB & WB & Row Total & User Accuracy \\
\hline NWB & 724 & 454 & 1178 & $61.46 \%$ \\
\hline WB & 216 & 239 & 455 & $52.52 \%$ \\
\hline Column total & 940 & 693 & 1633 & \\
\hline Producer Accuracy & $77.02 \%$ & & Overall Accuracy & $58.97 \%$ \\
\hline \multicolumn{7}{|l}{ Kappa $=0.121 ;$ SE of kappa $=0.024 ; 95 \%$ confidence interval: $0.074-$ to 0.167} \\
\hline
\end{tabular}

Accuracy assessment help quantify how good a job the classifier did. In our case, accuracy assessment and kappa value are low. The strength of agreement is considered satisfactory. This satisfactory result could be because of the limitations of the OBIA using the ENVI Zoom 4.5 software. The details of the limitation are discussed in the section below.

\subsubsection{Limitations of OBIA using The ENVI Zoom 4.5}

We re-sampled the original image to reduce the size of the image and to make it compatible for the software. On one hand, it helped the classification process by transforming the feature of interest, windbreaks, into more homogeneous areas to facilitate the image segmentation. However, the segmentation process failed to identify the younger windbreaks, 5 years or younger due to resampling. The other issue related to this method is demarcation of the proper boundary of the windbreak. The boundary of the objects was inconsistent with that of actual windbreak features on the ground. When examining object-based results over the original NAIP image it was evident that some windbreaks were not captured in their entirety (Figure 3). Because a resample product was being used for image segmentation and windbreak classification, the segmentation process had difficulty recognizing very poor condition areas within a larger windbreak feature. This is due to the drastic change in spectral reflectance between a densely canopied area in windbreak and that of a degraded area where snags, gaps, and soils was sometimes visible. Figure 3 displays a subset of the Ford County image where the segmentation process defined the border of a dense windbreak very well compared to another site where an inaccurate border was identified for a degraded windbreak. 

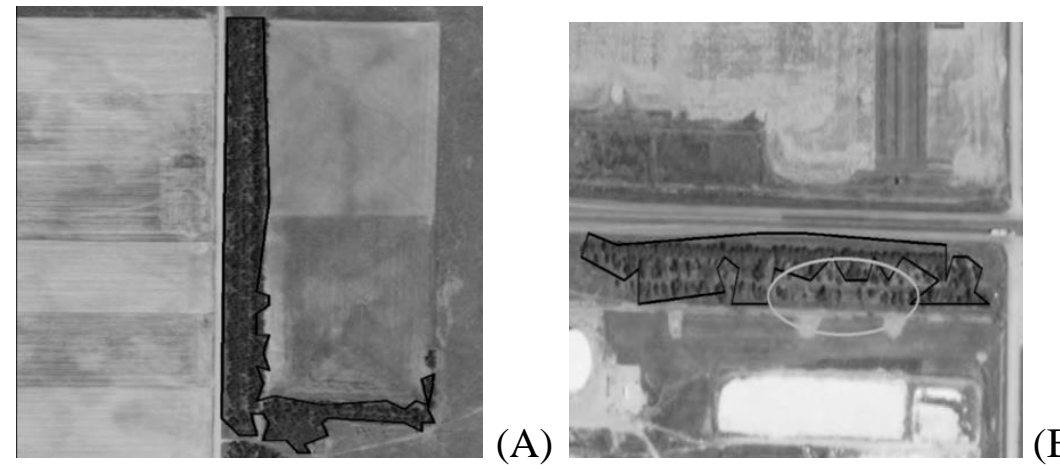

(B)

FIGURE 3: ACCURATE (A) AND INACCURATE (B) WINDBREAK BORDER ASSIGNMENTS

To correct the error and complement the shortcomings of ENVI Zoom software and OBIA method we used various tools and techniques in ArcGIS.

\subsection{Post classification process}

\subsubsection{Heads-up digitization, boundary editing and area calculation in ArcGIS}

Heads-up digitization is a process of converting the geographic features (windbreaks) using a raster data (Original NAIP imagery, $1 \mathrm{~m}$ resolution) into vectors by tracing a mouse over features displayed on a computer monitor in ArcGIS (ESRI, 2011). We used this method to create windbreaks that were missed during the classification process. Heads-up digitizing was also helpful in capturing younger windbreaks, which were missed because of the re-sampling done during preprocessing of images. This method complemented the shortcomings of ENVI Zoom software and was one of the few available options to generate complete inventory of the windbreaks in the study area. Digitizing the image to include missed windbreaks is far less time consuming and cost effective as compared to visiting and identifying each of the windbreaks on the ground.

We also used the editor tool and a smoothing technique in ArcGIS to merge the fragmented windbreaks and correct the boundaries demarcation.

\subsection{Field Survey}

Remote sensing accuracy assessments usually, if not always, require the use of ground truth data for comparison purposes. To validate our results we visited 10-12\% percent of the 
windbreaks identified through image analysis in each county. The other purpose of the field survey was to identify windbreak condition on the ground and their primary function. We visited more than 300 windbreaks in the field to collect information. Published in the Great Plains initiative Inventory Project Guide 1.0 (2008), foresters developed a set of criteria that are used when performing field surveys of windbreaks. We used the same criteria to collect the ground information, such as primary function, condition, length and perimeter of windbreaks. Many of the windbreaks were located on private property; therefore, prior permission from the landowners was obtained to access the windbreaks in the field.

\section{RESULTS AND DISCUSSION}

Object-based approach to classifying windbreaks began with raw imagery and produced a result in a couple of hours of computer processing time. This combined with "heads-up" digitizing in GIS, the preferred means to identify windbreak location for many applications created an excellent windbreak inventory in Kansas. The methods identified geospatial locations of 4592 windbreaks in fourteen counties in Western Kansas (Figure 4). Once we finalized the number of windbreaks and their location, we calculated area for each windbreak using the ArcGIS utility tool. These windbreaks cover approximately an area of 2596 hectares (Table 3). The combined results of the OBIA and digitizing process have generated an excellent inventory of windbreaks in each of the fourteen counties with overall accuracy of $96 \%$. 


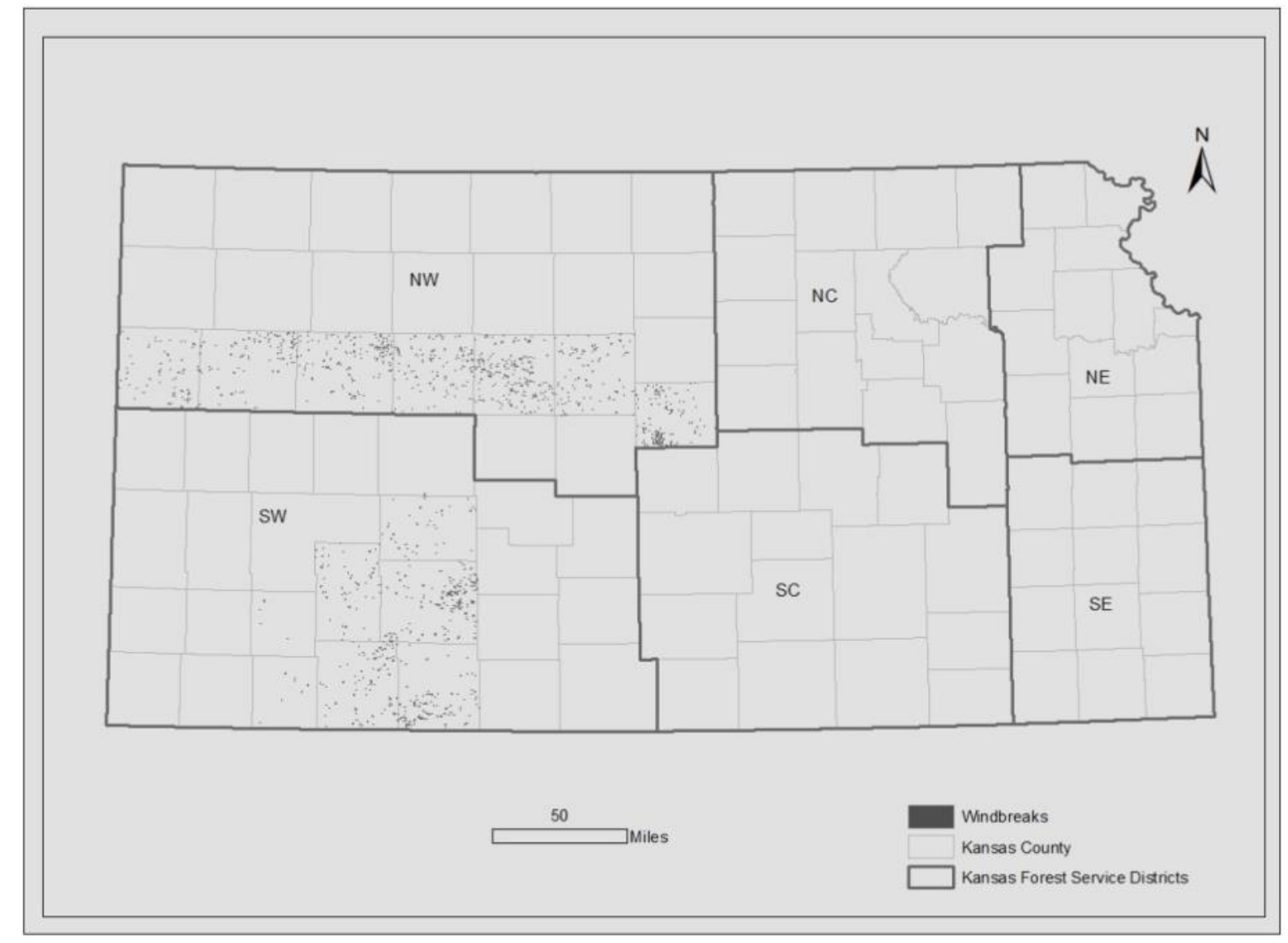

FIGURE 4: LOCATION OF WINDBREAKS IN FOURTEEN COUNTIES OF KANSAS

TABLE 3: FINAL NUMBER OF WINDBREAKS AND THE AREA COVERED BY THESE WINDBREAKS IN THE STUDY AREA

\begin{tabular}{|l|l|l|l|}
\hline County & \multirow{2}{*}{$\begin{array}{l}\text { No of } \\
\text { Windbreaks }\end{array}$} & \multicolumn{2}{|l|}{ Area covered by Windbreaks } \\
\cline { 3 - 4 } & Acres & Hectares \\
\hline Clark & 166 & 728.8169 & 294.941 \\
\hline Meade & 239 & 440.451 & 178.244 \\
\hline Seward & 29 & 26.170 & 10.590 \\
\hline Haskell & 22 & 26.9154 & 10.89 \\
\hline Gray & 196 & 222.5538 & 90.064 \\
\hline Ford & 316 & 1166.207 & 471.94 \\
\hline
\end{tabular}




\begin{tabular}{|l|l|l|l|}
\hline Hodgeman & 109 & 140.538 & 56.8737 \\
\hline Ellsworth & 512 & 701 & 284 \\
\hline Russell & 287 & 404.225 & 163.584 \\
\hline Ellis & 769 & 724.403 & 293.155 \\
\hline Trego & 504 & 473.483 & 191.612 \\
\hline Gove & 645 & 522.774 & 211.559 \\
\hline Logan & 462 & 488.468 & 197.676 \\
\hline Wallace & 336 & 349.141 & 141.292 \\
\hline Total & $\mathbf{4 5 9 2}$ & $\mathbf{6 2 6 9 . 4 5 3 1}$ & $\mathbf{2 5 3 7 . 1 5 3}$ \\
\hline
\end{tabular}

Once the area covered by the windbreaks was calculated, we were able to assign condition classes (good, fair and poor) to the windbreaks, based on the survey of selected samples on ground. The study summarized that out of 4592 windbreaks in the study area, $61 \%$ of the windbreaks are in good condition, $25 \%$ in fair condition and $14 \%$ of the windbreaks are in poor condition (FIGURE 5). We also categorize each of these 4592 windbreaks into farmstead, livestock, and field windbreaks, based on their primary function. The study revealed that $44 \%$ of windbreaks were farmstead, $42 \%$ were field windbreaks and $14 \%$ were serving livestock ((Figure 6).

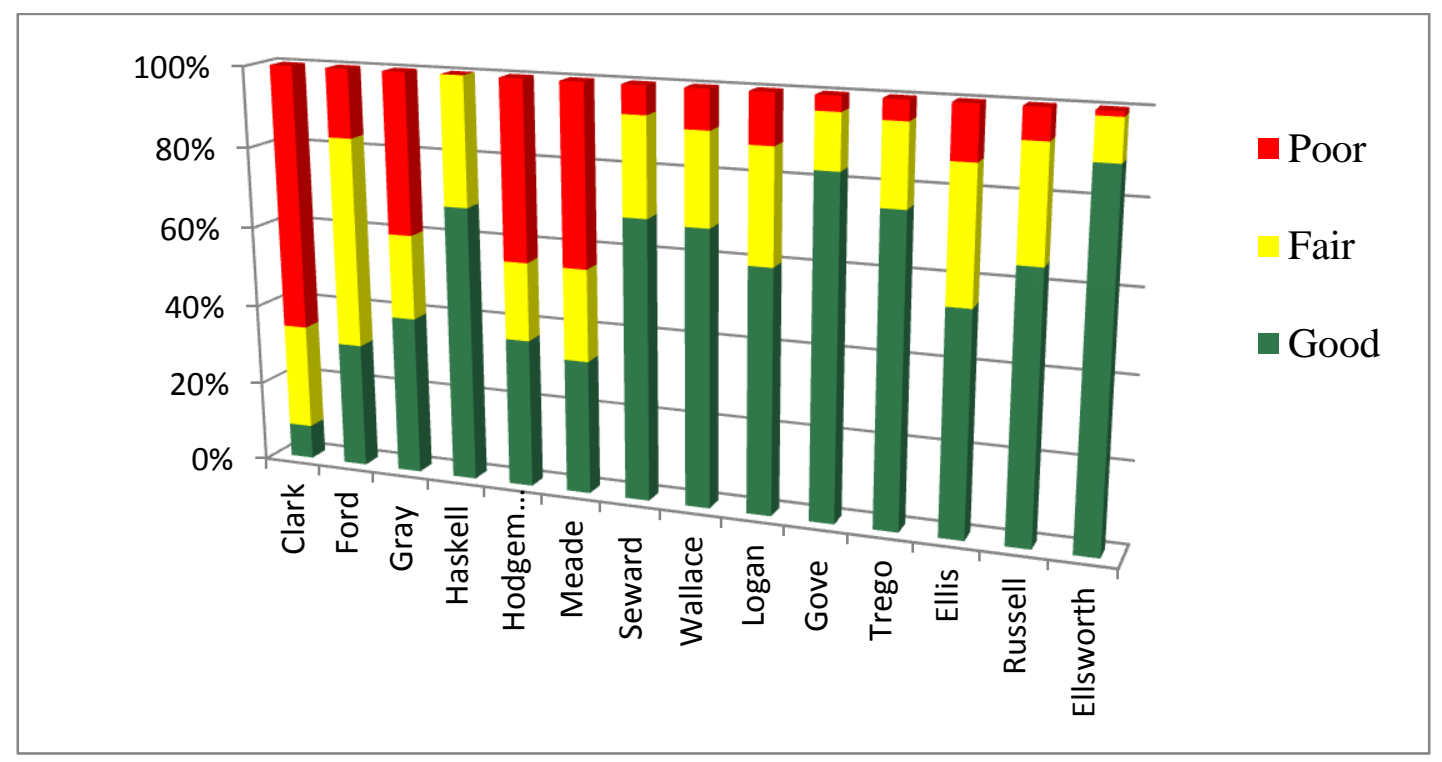

FIGURE 5: GROUND CONDITION OF WINDBREAKS BY COUNTY, KANSAS 


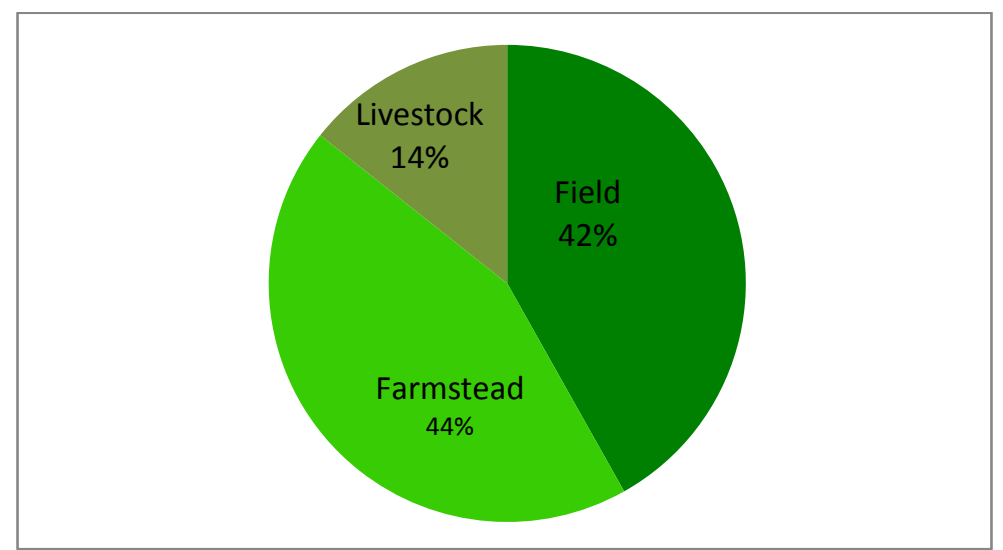

FIGURE 6: PRIMARY FUNCTION OF WINDBREAKS IN THE STUDY AREA

\section{CONCLUSION}

Reports from various agencies estimated that over $44 \%$ of Kansas windbreaks are in decline and in need of renovation. There is a little good science to efficiently document windbreak's exact location, size and specific condition. Therefore, it was timely to develop methods for the rapid identification of windbreak location. While a variety of windbreak surveys have been conducted in the past, none performed in Kansas have ever attempted to extract windbreaks from aerial imagery at the county level. Therefore, we used a remote sensing approach based on object-based image analysis to identify windbreaks visible in the color aerial imageries of NAIP. The method developed can be applied to identify the location of windbreaks in Kansas that other areas in the Great Plains region and beyond.

The object-based image analysis was successful in classifying and locating windbreaks with overall accuracy of $58.97 \%$ with Kappa value 0.121 . This assessment is satisfactory. Confusion between riparian areas, shrub patches and linear vegetated ditches along the road were the main source of error. The other error was younger windbreaks were missed during classification process. However, from practical point of view, the results received from the classification alone are significant. This process of windbreak identification is far less time consuming and cost effective as compared to visiting and identifying each of the windbreaks on the ground. 
Studies have suggested that resultant products from similar semi-automated methods are not sufficiently reliable to be of direct utility without some form of manual editing and revision (Benz et.al, 2004; Blashke, 2010 Tsai et al, 2011). Considerable manual editing is normal in case of image processing and photogrammetry. Therefore, heads-up digitization in ArcGIS is our current alternative to complement and compensate methodological limitation. We used heads-up digitization to include missed windbreaks. We also used the editor tool and a smoothing technique in ArcGIS to merge the fragmented windbreaks, correct the boundaries demarcation, and delete non-windbreak features classified as windbreaks. At the mean time, we continue to on improving the methodology to get better accuracy and desired results from OBIA.

OBIA combined with heads-up digitizing and editing tools in ArcGIS yielded desired results. The methods identified geospatial locations of 4592 windbreaks in fourteen counties in Western Kansas with overall accuracy of 96\%. The windbreaks cover approximate area of 2596 hectares. The field survey of selected samples supported our claim that 96 percent of the time windbreaks identified through digital image processing of NAIP images were correctly identified. Only $4 \%$ of the objects identified through NAIP image analysis were not windbreak. The $4 \%$ of the non-windbreak features classified as windbreaks were riparian area, shrub patches and/or fruit orchard.

We conclude that the OBIA combined with heads-up digitization proved successful at rapidly identifying windbreaks locations. The field survey of selected was crucial in validating the results obtained from the digital image processing. The survey was also helpful in identifying the primary function of windbreaks and their condition in the field. Therefore, similar methods can be used in future projects to locate windbreaks in other Kansas counties and across the Great Plains.

\section{FUNDING}

Funding for this project was provided by the Kansas Forest Service through the USDA State and Private Forestry Western Competitive Resource Allocation grant program. 


\section{REFERENCES}

Atchison. R.L., R.Daniels and E. Martinson. 2010. Kansas Forest Action Plan (KFAP). Kansas Forest Resource Assessment and Strategy. Kansas State University. Manhattan. Kansas.

Baatz, M., U. Benz, S. Dehghani, M. Heynen, A. Höltje, P. Hofmann, I. Lingenfelder, M. Mimler, M. Sohlbach, M. Weber, and G. Willhauck. 2004, eCognition Professional: User Guide 4 . Munich: Definiens-Imaging. http://www.gis.unbc.ca/help/software/ecognition4/ELuserguide.pdf (Last Accessed February 27, 2014).

Benz, U.C, P.Hofmann., G. Willhauck., I.Lingenfelder., M.Heynen. 2004.Multi-resolution, objectoriented fuzzy analysis of remote sensing data for GIS-ready information. Journal o of Photogrammetry and Remote Sensing. 58. 239-258

Blaschke, T. 2010. Object-based image analysis for remote sensing. ISPRS Journal of Photogrammetry and Remote Sensing. 65. 2-16

Brandle, J.R., L. Hodges, and X.H. Zhou. 2004. Windbreaks in North American agricultural systems. Agroforestry Systems 61: 65-78.

Cable, Ted .T. 1999. Nonagricultural Benefits of Windbreaks in Kansas. Great Plain Research: A Journal of Natural and Social Sciences. Paper 417. 41-55

Castonguay T.L and M.H. Hansen. 1984. Wooded Stripes and Windbreaks in Kansas, 1981. Research Notes. NC313. North Central Forest Experiment Station. USDA. Saint Paul. MN

Congalton, R.G. 1991. A review of assessing the accuracy of classifications of remotely sensed data. Remote Sensing of the Environment 37: 35-46.

Congalton, R.G. and K. Green. 1999. Assessing the Accuracy of Remotely Sensed Data: Principles and Practices. Boca Raton, FL: Lewis Publishers. 137p

Croker, T. 1991. The Great Plains Shelterbelt. Greeneville, TN: Artistic Printers.

Dodgson, N.A. 1992. Image Re-sampling. Technical Report: Number 261. Cambridge: University of Cambridge.

Droze, W.H. 1977. Trees, Prairies, and People: A History of Tree Planting in the Plains States. USDA Forest Service and Texas Woman's University Press, Denton, TX . 331.

ESRI 2011. ArcGIS Desktop: Release 10. Redlands, CA: Environmental Systems Research Institute. 
Famiglietti, J.S., J.A. Devereaux, C.A. Laymon, T. Tsegaye, P.R. Houser, T. J. Jackson, S.T. Graham, M. Rodell, and P.J. van Oevelen. 1999. Ground-based investigation of soil moisture variability within remote sensing footprints during the Southern Great Plains 1997 (SGP97) Hydrology Experiment. Water Resources Research. 35 (6): 1839 -1851

Fitzpatrick-Lins, K. 1981. Comparison of sampling procedures and data analysis for a land-use and land-cover map. Photogrammetric Engineering and Remote Sensing 47(3):343-351.

Goodin D.G., J. Harrington Jr., and B. Rundquist. 2002. Land cover change and associated trends in surface reflectivity and vegetation index in southwest Kansas: 1972-1992. Geocarto International 17(1):45-52.

Grala, R.K and J.C. Tyndall. 2010. Impact of field windbreaks on visual appearance of agricultural lands. Agroforestry systems. 80: 411-422

Harrington L.M.B. 2001. Attitudes toward climate change: major emitters in southwestern Kansas. Climate Research. 16:113-122. 341

Hsu, Chih-Wei., C-C, Chang, and C-J, Lin. 2008. A Practical Guide to Support Vector Classification. Department of Computer Science, National Taiwan University, Taipei, Taiwan. (http://www.csie.ntu.edu.tw/ cjlin)

Huang, X. and L. Zhang. 2008. An adaptive mean shift analysis approach for object extraction and classification from urban hyperspectral imagery. IEEE Transactions on Geoscience and Remote Sensing 46(12):4173-4185

ITT Visual Information Solutions. 2007. An Interval Based Attribute Ranking Technique. ITT-VIS White Paper, July.

Jager, G. and U. Benz. 2000. Measures of classification accuracy based on fuzzy similarity. IEEE Transactions on Geo science and Remote Sensing. 38 (3):1462-1467.

Jensen, J.R. 2005. Introductory Digital Image Processing: A Remote Sensing Perspective (3rd ed). Upper Saddle River, NJ: Prentice Hall.

Koch, D.E., R.L. Mohler, and D. Goodin. 2007. Stratifying land use/land cover for spatial analysis of disease ecology and risk: An example using object-based classification techniques. Geospatial Health 2(1):15-28. 
Kort, J. and C. Stefner. 2007. A Protocol for Shelterbelt Assessment Related to its Function. When Trees and Crops Get Together. Proceedings of the 10th North American Agroforestry Conference, Québec City, Canada, June 10-13.

Natural Resource Inventory (NRI), NRCS .2010. Soil Erosion in Cropland. http://www.nrcs.usda.gov/technical/NRI/ (Accessed August 2013)

Parker, J.A., R.V. Kenyon, and D.E. Troxel. 1983. Comparison of Interpolating Methods for Image Resampling. IEEE Transactions on Medical Imaging MI-2(1):31-39.

Prairie States Forest Project (PSFP).1937. Forestry For the Great Plains. USDA Forest Service. Nebraska, Lincoln.

Quam, V., L. Johnson., B. Wight., J. R. Brandle. 1994. Windbreaks for Livestock Operations. Natural resources. University of Nebraska Extension EC 94 -1766-X.

Quattrochi, D.A., S.J. Walsh, J.R. Jensen, and M.K. Ridd. 2003. Remote Sensing. Chapter 25 in Geography in America, Gaile, G. and C.J. Wilmot, eds. Oxford: Oxford University Press.

Radoux, J and P. Defourny.2007. A quantitative assessment of boundaries in automated forest stand delineation using very high resolution imagery. Remote Sensing of Environment. 110:468-475

Read, R. 1958. The Great Plains Shelterbelt in 1954: A Re-evaluation of Field Windbreaks Planted between 1935 and 1942 and a Suggested Research Program. Great Plains Agricultural Council No. 16.

Richards, J.A., J. Xiuping. 2005. Remote Sensing digital Image Analysis: An Introduction (4th Edition). Berlin: Springer-Verlag.

Robinson, D.J., N.J. Redding, and D.J. Crisp. 2002. Implementation of a fast algorithm for segmenting SAR imagery. Scientific and Technical Report, Defense Science and Technology Organization, Australia, January 1, 2002.

Rutherford, P. and L. Rapoza.2008. An evaluation of an object-oriented paradigm for land use/land cover classification. The professional Geographer.60(1)87-100

SAF. 2008. Windbreak. http://dictionaryofforestry.org/dict/term/windbreak. Accessed May15, 2014

Sorenson, C.J., and G.A. Marotz. 1977. Changes in shelterbelt mileage statistics over four decades in Kansas. Journal of Soil and Water Conservation 32(6):276-281. 
Tian, J. and D. M. Chen. 2007. Optimization in multi-scale segmentation of high- resolution satellite images for artificial feature recognition. International Journal of Remote Sensing. 28(20): 46254644.

Tsai, Y.H., D.Stow., and J.Weeks.2011. Comparison of Object-Based Image Analysis Approaches to Mapping New Buildings in Accra, Ghana Using Multi-Temporal QuickBird Satallite Imagery. Remote Sensing. 3. 2707-2726

Tyndall, J. 2009. Characterizing pork producer demand for shelterbelts to mitigate odor: an Iowa case study. Agroforestry Systems. 77: 205 -221.

US. Department of Agriculture (USDA). 1980. Field Windbreak removals in five Great Plains States, 1970-1975. Washington, D.C. Government Printing Office

United States Department of Agriculture (USDA). 1994. Summary Report 1992 National Resources Inventory. Washington, DC: U.S. Government Printing Office.

United States Department of Agriculture (USDA). 2007. Summary Report 2007National Resources Inventory. Washington, DC: U.S. Government Printing Office.

Wang, F. 1990. Improving remote-sensing image -analysis through fuzzy information representation. Photogrammetric Engineering and Remote Sensing 56 (8):1163-1169

Wiseman, G.S., J. Kort, D.J. Walker, J.S. Powers and C.N. Stefner. 2007. Quantification of Shelterbelt Characteristics using High Resolution Imagery. When Tree and Crops Get Together. Proceedings of the 10th North American Agroforestry Conference, Quebec City, Canada, June $10-13$

Williams, K and D.Davis. 2013. National Agriculture Imagery Program (NAIP) Information Sheet. United States Department of Agriculture.

http://www.fsa.usda.gov/Internet/FSA_File/naip_info_sheet_2013.pdf (Last accessed February 27, 2014) 